\title{
Breast Cancer in Patients 80 Years-Old and Older
}

\author{
Aaron Bertolo $^{1}$ (D), Christopher Rosso ${ }^{2}$ (D), Ioannis A. Voutsadakis ${ }^{3,4}$ (iD \\ ${ }^{1}$ St. George University School of Medicine, Grenada \\ ${ }^{2}$ Algoma University, Sault Ste. Marie, Ontario, Canada \\ ${ }^{3}$ Algoma District Cancer Program, Sault Area Hospital, Sault Ste. Marie, Ontario, Canada \\ ${ }^{4}$ Section of Internal Medicine, Division of Clinical Sciences, Northern Ontario School of Medicine, Sudbury, Ontario, Canada
}

\begin{abstract}
Objective: Breast cancer is the most common cancer in women and one in ten patients affected are over age 80 . However, this age group is mostly excluded from clinical trials and data to inform their care is sparse.
\end{abstract}

Materials and Methods: Medical records of all patients aged 80 years-old and older diagnosed and treated for breast cancer in a single center over a six-year period were retrospectively reviewed. A cohort of patients aged 65 to 75 treated for breast cancer at the same center during the same period was also reviewed for comparison.

Results: Patients in the 80 and over age group were commonly diagnosed with stage II or III disease (39.2\%) compared to younger patients who were diagnosed more commonly $(61.6 \%)$ with stage I disease. Sub-types of breast cancer had a similar representation in the two groups. Hormonal therapy was used equally in the two groups, but significantly fewer patients in the 80 and over age group had radiation therapy and chemotherapy as part of their treatment. Despite these differences, recurrence rates were not significantly different between the two groups.

Conclusion: Individualized treatments taking into consideration the patient's general status, comorbidities and life expectancy are feasible in the older breast cancer population and result in outcomes similar to those of younger patients in the short and intermediate terms.

Keywords: Breast cancer, chemotherapy, geriatric, octogenarians, radiotherapy, retrospective

Cite this articles as: Bertolo A, Rosso C, Voutsadakis IA. Breast Cancer in Patients 80 Years-Old and Older. Eur J Breast Health 2020; 16(3): 208-212.

\section{Introduction}

Cancer is commonly a disease of the old and the median age at diagnosis of all sites is 65 years-old, according to U.S. SEER data (1). Several common cancers, such as lung carcinomas, prostate cancer, and gastrointestinal cancer, present at the median age of 65 years and older. Although the median age at presentation of breast cancer is 61 years, $45 \%$ of breast cancer patients are 65 years and older (2). Older patients ( $\geq 80$ years-old) constitute a significant percentage of these patients. About one in four patients with breast cancer above age 65 or $10.6 \%$ of the total breast cancer population is 80 years-old or older (3). This age group often presents challenges in their treatment because of comorbidities and frailty. Studies have also found that diagnosis is commonly delayed due to reduced screening (4). Challenges include cardiovascular and cerebrovascular comorbidities that preclude general anesthesia for surgical treatment and may increase adverse effects of chemotherapy treatment. Many patients, especially in the older part of the age spectrum ( $>85$ years-old), would not be considered for chemotherapy treatment by most oncologists, even when an oncologic indication exists, because of a perceived or actual increase in adverse effects of such therapy. Elderly patients may also be more prone to the adverse effects of hormonal treatment, such as neurocognitive function decline and aromatase inhibitor-associated osteoporosis. Overall, these challenges could lead to inferior outcomes of breast cancer in the elderly, and such outcomes may be improved by better-tailored therapies that take into consideration the functional status and organ reserves of the individual patient rather than the numeric age (5).

A few older and more contemporary studies have addressed the particular presentation and treatment characteristics of breast cancer in the older population (6-9). Breast cancer in this population tends to present later and may receive less than standard surgical treatment due to comorbidities or perceptions of the surgeon (5). They also tend to receive less often chemotherapy or radiation (7). 
Further information on clinical, sub-type and therapy characteristics in a modern series of elderly breast cancer patients is presented in this paper and comparisons are drawn with younger patients treated concomitantly in a single center. As options of systemic treatment beyond hormonal therapy and chemotherapy increase in breast cancer and include targeted treatments and immunotherapy, an improved understanding of the disease in the elderly will help with better tailoring of therapies $(10,11)$.

\section{Materials and Methods}

A retrospective review of patient case records was performed to identify patients over 80 years-old treated for breast cancer at our center between August 2013 and March 2019. Charts were reviewed, and data on key demographic and tumor characteristics of interest were recorded and analyzed. A similar group of patients with breast cancer but aged 65 to 75 treated at the same period were selected and analyzed for comparison. For each patient older than 80 years of age, a patient aged 65 to 75 included in the database and diagnosed as close as possible was selected for inclusion in the comparison group. Demographic data were captured from patient medical records, as well as data on the histologic characteristics of tumors, stage, tumor markers and molecular characteristics, including Estrogen Receptor (ER), Progesterone Receptor (PR) and Human Epidermal Growth Factor Receptor 2 (HER2) expression. Histoscores for ER and PR were calculated as the product of the percentage of cells staining positive for the receptors multiplied by the staining intensity (strong intensity $=3$, moderate intensity $=2$, weak intensity of staining $=1$ ). Data on patient treatments and outcomes were also extracted from electronic medical records.

\section{Statistical analysis}

Descriptive statistics were used for the summary of the variables of interest. The $\mathrm{x}^{2}$ test or Fisher's exact test was used to evaluate differences in clinical and biologic characteristics of patients with or without outcomes of interest. Continuous parameters were compared with the $\mathrm{t}$ test. The Kaplan-Meier method was used for the construction of OS and PFS curves. All resulting p values were considered to be significant at the level of $\mathrm{p}<0.05$.

The protocol of the study was approved by the Research Ethics Board of the institution (\# 2019-07-01).

\section{Results}

Ninety-seven patients 80 years-old and older (older group) were treated for a breast cancer and are analyzed. A similar group of breast cancer patients age 65 to 75 (younger group) treated over the same period

\section{Key Points}

- Occurrence of breast cancer should not be underestimated in the population of women above 80 years of age.

- Breast cancer is diagnosed more commonly clinically rather than with screening in women older than 80 years of age.

- The biology of breast cancer is not significantly different in women 80 years-old and older compared with younger post-menopausal women.

- Breast cancer patients 80 years-old and older receive hormonal therapies in a comparative rate with younger patients but they receive radiation therapy and chemotherapy less commonly than younger counterparts. were analyzed as a comparison. The median age of the older group was 85 years-old (range, $80-97$ ). Eighty-five patients (87.6\%) were 80 to 89 years-old, and 12 patients (12.4\%) were 90 years-old and older. The median age of the younger group was 70 years-old (range, 65-75) (Table 1). A significantly higher percentage of older patients $(88.7 \%)$ had their cancer diagnosed clinically as opposed to diagnosis through screening compared with the younger patient group in whom the cancer was most commonly (54.5\% of cases) diagnosed with screening. Consistently, there was also a difference in the two groups in the stage of cancer at diagnosis. Most breast cancers in the younger group $(67.7 \%)$ were diagnosed as in situ disease or stage I, whereas in the older group, this percentage was $43.3 \%(\mathrm{p}=0.01$, Table 1$)$. A significant proportion of the older patients $(15.4 \%)$ were not completely staged pathologically as no intervention beyond the biopsy of the primary tumor was performed. No significant differences were observed between the groups in tumor grade, histologic type or biologic sub-type. There were also no significant differences between the groups regarding ER and PR positivity.

The older group also exhibited a heavier comorbidity burden than the younger group, including heart disease and kidney disease and a trend (although not statistically significant) for higher rates of hypertension and diabetes (Table 2). The median number of comorbidities was 3 (range, 0-10) in the older group and 2 (range, 0-10) in the younger group $(\mathrm{p}<0.0001)$. Patients in the older age group were receiving a higher average number of medications (median: 5 , range: $0-14$ ) than patients in the younger group (mean: 3 , range: $0-13, \mathrm{p}=0.001)$.

The older group of patients received more commonly a mastectomy (33\% of patients versus $23.2 \%$ of patients in the younger group), whereas the reverse was true for a lumpectomy $(\mathrm{p}=0.02$, Table 3$)$. Older patients had also more commonly no surgical intervention at all (15.5\% of patients) or no axillary intervention (sentinel node biopsy or dissection). Among adjuvant therapies, hormonal therapy was equally used between the groups; however, adjuvant radiation and chemotherapy were less used in the older group (33\% versus $75.8 \%$ for radiation and $11.3 \%$ versus $35.4 \%$ for chemotherapy, Table 3).

The median follow-up in the older group was 22.6 months (range, 0 -120 months), and the median follow-up in the younger group was 34.8 months (range, $0-135$ months). Outcomes were overall positive in both groups, with 13 patients in the older group and four patients in the younger group having tumor recurrence or progression. Overall Survival (OS) was acceptable for both groups but better for the younger group due to competing causes of death in the older patients (Figure 1).

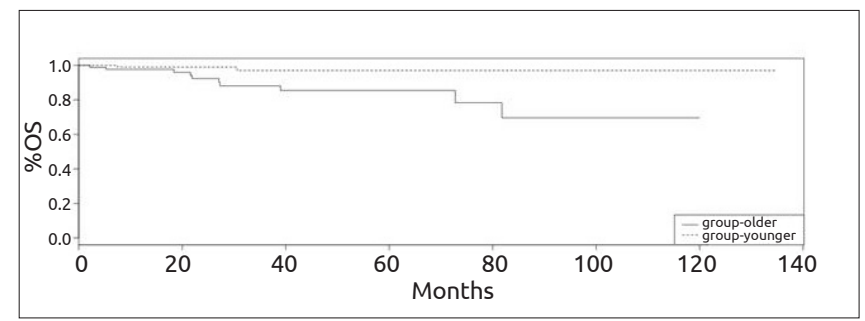

Figure 1. Overall Survival of patients with breast cancer оver 80 years-old (group-older) versus patients 65 to 75 years-old (groupyounger). Log Rank $p=0.007$ 
Table 1. Patient and disease characteristics in patients with breast cancer over 80 years-old versus patients 65 to 75 years-old

\begin{tabular}{|c|c|c|c|}
\hline & $\begin{array}{l}\text { Group } \\
>80\end{array}$ & $\begin{array}{l}\text { Group } \\
65-75\end{array}$ & $\mathbf{p}$ \\
\hline \multicolumn{4}{|l|}{ Age } \\
\hline $\begin{array}{l}\text { Median age at diagnosis } \\
\text { (range) }\end{array}$ & $85(80-97)$ & $70(65-75)$ & \\
\hline \multicolumn{4}{|l|}{ Mode of Detection } \\
\hline Screening & $11(11.3 \%)$ & $54(54.5 \%)$ & $<0.000$ \\
\hline Clinical & $86(88.7 \%)$ & $45(45.5 \%)$ & \\
\hline \multicolumn{4}{|l|}{ Stage } \\
\hline 0 & $8(8.2 \%)$ & $6(6.1 \%)$ & 0.01 \\
\hline I & $34(35.1 \%)$ & $61(61.6 \%)$ & \\
\hline II & $35(36.1 \%)$ & $22(22.2 \%)$ & \\
\hline III & $3(3.1 \%)$ & $8(8.1 \%)$ & \\
\hline IV & & $2(2.1 \%)$ & $1(1 \%)$ \\
\hline N/A & $15(15.4 \%)$ & $1(1 \%)$ & $<0.000$ \\
\hline \multicolumn{4}{|l|}{ Size } \\
\hline Median size (cm) (range) & $2.4(0.5-10)$ & $2.0(0.2-11.2)$ & 0.13 \\
\hline \multicolumn{4}{|l|}{ Grade } \\
\hline 1 & $8(8.2 \%)$ & $13(13.1 \%)$ & 0.82 \\
\hline 2 & $36(37.1 \%)$ & $43(43.5 \%)$ & \\
\hline 3 & $28(28.9 \%)$ & $34(34.3 \%)$ & \\
\hline N/A & $25(25.8 \%)$ & $9(9.1 \%)$ & \\
\hline \multicolumn{4}{|l|}{ Histology } \\
\hline Ductal & $67(69.1 \%)$ & $63(63.6 \%)$ & 0.10 \\
\hline Lobular & $9(9.2 \%)$ & $15(15.2 \%)$ & \\
\hline Mixed & $3(3.1 \%)$ & $11(11.1 \%)$ & \\
\hline Other & $6(6.2 \%)$ & $10(10.1 \%)$ & \\
\hline N/A & $12(12.4 \%)$ & 0 & \\
\hline \multicolumn{4}{|l|}{ Sub-Type } \\
\hline ER+/HER2- & $71(73.2 \%)$ & $72(72.7 \%)$ & 0.74 \\
\hline HER2+ & $12(12.4 \%)$ & $12(12.1 \%)$ & \\
\hline Triple Negative & $6(6.2 \%)$ & $9(9.1 \%)$ & \\
\hline N/A & $8(8.2 \%)$ & $6(6.1 \%)$ & \\
\hline \multicolumn{4}{|c|}{$\begin{array}{l}\text { The second comparison in stage refers to all patients } \\
\text { clinicopathologically staged versus not staged } \\
\text { N/A: not available; ER: estrogen receptor; HER2: human epidermal } \\
\text { growth factor receptor } 2\end{array}$} \\
\hline
\end{tabular}

\section{Discussion and Conclusion}

Octogenarians represent about one in ten patients with breast cancer. In the age group 80 to 84 years-old the incidence of breast cancer per 100,000 people is about 400 , which is similar to the incidence for the
Table 2. Comorbidities and polypharmacy in the group of patients with breast cancer over 80 yearsold versus patients 65 to 75 years-old

$\begin{array}{lccc}\text { Comorbidities } & \text { Group }>80 & \text { Group 65-75 } & \text { P } \\ \text { Heart disease } & 37(38.1 \%) & 13(13.1 \%) & <0.000 \\ \text { Diabetes } & 25(25.8 \%) & 15(15.2 \%) & 0.065 \\ \text { Hypertension } & 58(59.8 \%) & 47(47.5 \%) & 0.08 \\ \text { Lung disease } & 18(18.6 \%) & 17(17.2 \%) & 0.80 \\ \text { Kidney disease } & 10(10.3 \%) & 2(2 \%) & 0.01 \\ \begin{array}{l}\text { Previous cancer } \\ \text { Median number of }\end{array} & 13(13.4 \%) & 11(11.1 \%) & 0.62 \\ \text { comorbidities (range) } & 3(0-10) & 2(0-10) & <0.00 \\ \begin{array}{l}\text { Polypharmacy } \\ \multicolumn{1}{l}{\begin{array}{l}\text { Median number of } \\ \text { medications (range) }\end{array}}\end{array} & 5(0-14) & 3(0-13) & 0.001 \\ & & & \end{array}$

Table 3. Cancer treatments in the group of patients with breast cancer over 80 years-old versus patients 65 to 75 years-old

\begin{tabular}{|c|c|c|c|}
\hline Treatment & Group $>80$ & Group 65-75 & $\mathbf{p}$ \\
\hline \multicolumn{4}{|l|}{ Surgery } \\
\hline Lumpectomy & $50(51.5 \%)$ & 74 (74.8\%) & 0.02 \\
\hline Mastectomy & $32(33 \%)$ & $23(23.2 \%)$ & \\
\hline None & $15(15.5 \%)$ & $2(2 \%)$ & $<0.000$ \\
\hline No axillary intervention & 19 (19.6\%) & $7(7.1 \%)$ & 0.01 \\
\hline Hormonal therapy & 69 (71.1\%) & $74(74.7 \%)$ & 0.56 \\
\hline Radiation & $32(33 \%)$ & 75 (75.8\%) & $<0.000$ \\
\hline Chemotherapy & $11(11.3 \%)$ & 35 (35.4\%) & $<0.000$ \\
\hline
\end{tabular}

In the surgery comparisons the first comparison refers to lumpectomy versus mastectomy and the second comparison refers to any surgery (lumpectomy or mastectomy) versus no surgery

to 54 years-old in whom the incidence is just above 200 per 100,000 people (12). The disease may differ biologically in patients 80 years old and older. In addition, treatments in this instance have to take into consideration the particularities of this older population.

In this report, we investigated the characteristics, treatment and outcomes of breast cancer in octogenarians and nonagenarians and compared them with a similar group of younger patients aged 65 to 75 who were treated at our center during the same period. The main findings included that older patients were more commonly diagnosed clinically and with a stage II or III disease compared with younger patients who were diagnosed more commonly with screening and with stage I disease. Additionally, there were no significant differences in the histology or sub-type of tumors in the two groups. Older patients, as expected, had a higher number of comorbidities and took on average 1.5 more medications than younger patients. Regarding therapy, the group aged 80 and older underwent more commonly a mastectomy or no surgery 
as their primary surgical treatment, and a significant proportion, about one in five patients, did not have an axillary intervention. Radiation and chemotherapy were also used less in the older group compared with younger counterparts, aged 65 to 75 .

Given that guidelines do not advocate for the screening of breast cancer in women older than 75 or with a life expectancy of fewer than 10 years $(13,14)$, the finding of more advanced stage at diagnosis in older patients should not come as a surprise and is consistent with a higher percentage of clinically diagnosed cancers in these patients. Randomized trials of screening mammography have not included women above age 75 and only one trial included women above age 70 (15). Thus, benefit of screening in reducing mortality in women age 80 and above is uncertain.

Molecular characteristics of breast cancer in patients 80 years-old and older are similar in the older and younger group. This finding is consistent with the results of another series that compared 83 octogenarian breast cancer patients with a group of 249 breast cancer patients 60 to 70 years-old (7). In this series, hormone receptor-positive cancers were equally prevalent in patients older than 80 compared with patients aged 60 to 70 and similar to the prevalence of hormone receptor positivity in the current series. HER2 positivity was also not significantly different in the two groups (7). An additional report of 124 patients 80 years-old and older also confirmed HER2 positivity in 12\% (16). Another series compared women with breast cancer above 60 years-old with counterparts between ages 40 and 59 and those below age 40 (16). It found that the group diagnosed at age above 60 years-old had a higher percentage of ER/ PR positive tumors than patients aged 40 to 60 or younger. HER2 positive tumors were equally prevalent in the three groups (17). In contrast, a study from the Netherlands showed a higher prevalence of HER2 positive tumors $(22 \%)$ in women younger than 40 years-old compared with women over 70 years old who had HER 2 positive tumors in $10 \%$ of cases (18). The basal-like phenotype was observed in $13.4 \%$ of the breast cancers in patients older than 60 as opposed to $22.6 \%$ in patients 40 to 60 years-old (17). Regarding specific mutations, the tumor suppressor $\mathrm{p} 53$ gene was more commonly mutated in patients in the 40 - to 60 -year age group (41.5\% versus $29.1 \%$ ). However, mutations of the E-cadherin gene (CDH1) commonly associated with lobular histology and the luminal phenotypes were more prevalent in patients above age $60(19.3 \%$ versus $12.2 \%$ in younger patients) (17). Together, these findings suggest that there is a similarity between the breast cancer sub-type landscape in patients over 80 years of age and younger post-menopausal counterparts. Conversely, peri-menopausal and pre-menopausal patients have higher percentages of HER2 positive and triple-negative cancers.

Despite similarities of breast cancer biologic sub-types between women over 80 years-old and younger post-menopausal women, their treatment needs to be tailored due to increased comorbidities associated with decreased organ function reserves and frailty. We have observed a significant increase in comorbidities and polypharmacy in our older patients, which is consistent with previous research (7). As a result, decreased use of radiation therapy has been observed. However, in our series, this may also be justified by increased mastectomy use in older patients. A significantly decreased use of chemotherapy, despite similar tumor biology and higher tumor stage, is certainly due to concerns about the tolerability of treatment and possible effects for the performance status and self-sufficiency of patients (19). This finding is a legitimate concern even for patients in this age group who are initially entirely independent, as their ability to metabolize the drugs may be sub-optimal and exposure levels disproportionate (20). Geriatric assessment is an integral part of the care of older cancer patients and may accurately predict patients at higher risk for treatment toxicity (21-24). Reassuringly, although the Overall Survival of older patients was lower than that of the younger group, competing causes rather the breast cancer was more commonly the cause of their demise and, the recurrence rates were not different. In addition, the benefit of chemotherapy may not be as extensive in older patients, which would make the balance of risk- benefit less favorable $(8,25)$.

The main limitations of the current study include the retrospective nature of its design that may have introduced selection and recording bias and the moderate size that may have precluded detection of smaller differences between the groups. In addition, despite the fact that the study population is contemporary, new therapies that have been introduced recently such as CDK inhibitors, PI3K inhibitors and immune checkpoint inhibitors $(10,26-29)$ have not been included in the treatments that the patients, either in the older or the younger group, have received.

In conclusion, this study has shown that breast cancer in women who are 80 years-old and older is biologically similar to the disease in younger post-menopausal women but tends to present in more advanced stages possibly due to lower rates of screening in this population. Despite lower use of radiation and chemotherapy in patients 80 years-old and older, disease recurrence rates remain low, at least in the short-term. Individualized therapies that consider the patient's general status, comorbidities, and life expectancy remain the key for optimal outcomes, both from a cancer outcome perspective and from the perspective of preserving the quality of life and independence of the patient. Novel targeted cancer treatments with a better safety profile than standard chemotherapy will provide further opportunity for improving outcomes, especially for sub-types with limited options currently, such as triple-negative disease.

Ethics Committee Approval: Ethics committee approval was received for this study from the ethics committee of Saullt Area Hospital (\#2019-07-01).

Informed Consent: Written informed consent was not required or obtained from patients who participated in this study, as this was a retrospective investigation.

Peer-review: Externally peer-reviewed.

Author Contributions: Concept - I.A.V.; Design - I.A.V.; Supervision - I.A.V.; Resources - I.A.V.; Materials - I.A.V.; Data Collection and/or Processing - A.B., C.R.; Analysis and/or Interpretation - A.B., I.A.V.; Literature Search - A.B., I.A.V.; Writing Manuscript - I.A.V.; Critical Review - C.R., I.A.V.

Acknowledgements: The authors thank the Sault Ste. Marie Academic Medical Association, Sault Ste. Marie, Canada for administrative support.

Conflict of Interest: The authors have no conflicts of interest to declare.

Financial Disclosure: The authors declared that this study has received no financial support.

\section{References}

1. Howlander N, Noone AM, Krapcho M, Miller D, Brest A, Yu M, Ruhl J, Tatalovich Z, Mariotto A, Lewis DR, Chen HS, Feuer EJ, Cronin KA. SEER Cancer Statistics Review, 1975-2012. Available from: www.seer. cancer.gov

2. Miller KD, Siegel RL, Lin CC, Mariotto AB, Kramer JL, Rowland JH, Stein KD, Alteri R, Jemal A. Cancer treatment and survivorship statis- 
tics, 2016. CA Cancer J Clin 2016; 66: 271-289. (PMID: 27253694) [Crossref]

3. American College of Surgeons National Cancer Database Benchmark Reports. Available from: http://cromsell.org/ BMarks/BMPub

4. Butler AN. Screening mammography for older women: a case of mixed messages. Arch Intern Med 1992; 152: 922-925. (PMID: 1580716) [Crossref]

5. Ulcickas Yood M, Owusu C, Buist DSM, Geiger AM, Field TS, Thwin SS, Lash TL, Prout MN, Wei F, Quinn VP, Frost FJ, Silliman RA. Mortality impact of less-than-standard therapy in older breast cancer patients. J Am Coll Surg 2008; 206: 66-75. (PMID: 18155570) [Crossref]

6. Guilfoyle C, Keller D, Sariego J. Breast cancer in the octogenarian. Breast J 2012; 18: 650-651. (PMID: 23110369) [Crossref]

7. Kuzan TY, Koca E, Dizdar O, Arslan C, Eren T, Yalcin S, Kucukoztas N, Aksoy S, Rahatli S, Dede DS, Altundag O, Zengin N, Ozyilkan O, Altundag K. Breast cancer in octogenarian women: clinical characteristics and outcome. J BUON 2013; 18: 328-334. (PMID: 23818342)

8. Martinez-Ramos D, Simon-Monterde L, Queralt-Martin R, SuelvesPiqueres C, Menor-Duran P, Escrig-Sos J. Breast cancer in octogenarian. Are we doing our best? A population-registry based study. Breast 2018; 38: 81-85. (PMID: 29274475) [Crossref]

9. Mamtani A, Gonzalez JJ, Neo DT, Friedman RS, Recht A, Hacker MR, Sharma R. Treatment strategies in octogenarians with early-stage, high-risk breast cancer. Ann Surg Oncol 2018; 25: 1495-1501. (PMID: 29427213) [Crossref]

10. Voutsadakis IA. Immune blockade inhibition in breast cancer. Anticancer Res 2016; 36: 5607-5622. (PMID: 27793883) [Crossref]

11. Finn RS, Martin M, Rugo HS, Jones S, Im SA, Gelmon K, Harbeck N, Lipatov ON, Walshe JM, Moulder S, Gauthier E, Lu DR, Randolph S, Diéras V, Slamon DJ. Palbociclib and letrozole in advanced breast cancer. N Engl J Med 2016; 375: 1925-1936. (PMID: 27959613) [Crossref]

12. Strulov Shachar S, Hurria A, Muss HB. Breast cancer in women older than 80 years. J Oncol Practice 2016; 12: 123-132. (PMID: 26869650) [Crossref]

13. Cancer Care Ontario Breast Cancer Pathway Map. Available from: www. cancercareontario.ca/en/pathwaymap. Assessed March 12, 2020.

14. Oeffinger KC, Fortham ET, Etzioni R, Herzig A, Michaelson JS, Shih YC, Walter LC, Church TR, Flowers CR, LaMonte SJ, Wolf AM, DeSantis C, Lortet-Tieulent J, Andrews K, Manassaram-Baptiste D, Saslow D, Smith RA, Brawley OW, Wender R; American Cancer Society. Breast cancer screening for women at average risk: 2015 guideline update from the American Cancer Society. JAMA 2015; 314: 1599-1614. (PMID: 26501536) [Crossref]

15. Kotwal AA, Schonberg MA. Cancer screening in the elderly. A review of breast, colorectal, lung, and prostate cancer screening. Cancer J 2017; 23: 246-253. (PMID: 28731949) [Crossref]

16. Ferrigni E, Bergom C, Yin Z, Szabo A, Kong AL. Breast cancer in women aged 80 years or older: An analysis of treatment patterns and disease outcomes. Clin Breast Cancer 2019; 19: 157-164. (PMID: 30819504) [Crossref]

17. Wang MX, Ren JT, Tang LY, Ren ZF. Molecular features in young vs elderly breast cancer patients and the impacts on survival disparities by age at diagnosis. Cancer Medicine 2018; 7: 3269-3277. (PMID: 29761914) [Crossref]
18. de Munck L, Schaapveld M, Siesling S, Wesseling J, Voogd AC, TjanHeijnen VC, Otter R, Willemse PH. Implementation of trastuzumab in conjunction with adjuvant chemotherapy in the treatment of non-metastatic breast cancer in the Netherlands. Breast Cancer Res Treat 2011; 129: 229-233. (PMID: 21431871) [Crossref]

19. Balducci L. Treatment of breast cancer in women older than 80 years is a complex task. J Oncol Practice 2016; 12: 133-134. (PMID: 26869651) [Crossref]

20. Wasil T, Lichtman SM. Clinical pharmacology issues relevant to the dosing and toxicity of chemotherapy drugs in the elderly. Oncologist 2005; 10: 602-612. (PMID: 16177284) [Crossref]

21. Extermann M, Boler I, Reich RR, Lyman GH, Brown RH, DeFelice J, Levine RM, Lubiner ET, Reyes P, Schreiber FJ 3rd, Balducci L. Predicting the risk of chemotherapy toxicity in older patients: The chemotherapy Risk Assessment Scale for High-Age patients (CRASH) score. Cancer 2012; 118: 3377-3386. (PMID: 22072065) [Crossref]

22. Hurria A, Togawa K, Mohile SG, Owusu C, Klepin HD, Gross CP, Lichtman SM, Gajra A, Bhatia S, Katheria V, Klapper S, Hansen K, Ramani R, Lachs M, Wong FL, Tew WP. Predicting chemotherapy toxicity in older adults with cancer: A prospective multicenter study. J Clin Oncol 2011; 29: 3457-3465. (PMID: 21810685) [Crossref]

23. Voutsadakis IA. Clinical tools for chemotherapy toxicity prediction and survival in geriatric cancer patients. J Chemother 2018; 30: 266-279. (PMID: 29943680) [Crossref]

24. Reed M, Patrick C, Quevillon T, Walde N, Voutsadakis IA. Prediction of hospital admissions and grade 3-4 toxicities in cancer patients 70 years-old and older receiving chemotherapy. Eur J Cancer Care 2019; 28: e13144. (PMID: 31429128) [Crossref]

25. Chou HH, Kuo WL, Yu CC, Tsai HP, Shen SC, Chu CH, Yu MC, Lo YF, Dabora MA, Chang HK, Lin YC, Ueng SH, Chen SC. Impact of age on pathological complete response and locoregional recurrence in locally advanced breast cancer after neoadjuvant chemotherapy. Biomed J 2019; 42: 66-74. (PMID: 30987708) [Crossref]

26. Etti J. Management of adverse events due to cyclin-dependent kinase 4/6 inhibitors. Breast Care 2019; 14: 86-92. (PMID: 31798379) [Crossref]

27. Spring LM, Wander SA, Andre F, Moy B, Turner NC, Bardia A. Cyclindependent kinase 4 and 6 inhibitors for hormone receptor-positive breast cancer: past, present, and future. Lancet 2020; 395: 817-827. (PMID: 32145796) [Crossref]

28. André F, Ciruelos E, Rubovszky G, Campone M, Loibl S, Rugo HS, Iwata H, Conte P, Mayer IA, Kaufman B, Yamashita T, Lu YS, Inoue K, Takahashi M, Pápai Z, Longin AS, Mills D, Wilke C, Hirawat S, Juric D, SOLAR-1 Study Group. Alpelisib for PIK3CA-mutated, hormone receptor-positive advanced breast cancer. N Engl J Med 2019; 380: 19291940. (PMID: 31091374) [Crossref]

29. Schmid P, Rugo HS, Adams S, Schneeweiss A, Barrios CH, Iwata $\mathrm{H}$, Diéras V, Henschel V, Molinero L, Chui SY, Maiya V, Husain A, Winer EP, Loi S, Emens LA, IMpassion130 Investigators. Atezolizumab plus nab-paclitaxel as first-line treatment for unresectable, locally advanced or metastatic triple-negative breast cancer (Impassion130): updated efficacy results from a randomised, double-blind, placebo-controlled, phase 3 trial. Lancet Oncol 2020; 21: 44-59. (PMID: 31786121) [Crossref] 